\title{
ANALISIS PEMANFAATAN SOCIAL COMMERCE BAGI UMKM: ANTESEDEN DAN KONSEKUEN
}

\author{
Anissa Hakim Purwantini*, Friztina Anisa \\ Universitas Muhammadiyah Magelang \\ *anissa.hakim@ummgl.ac.id
}

\begin{abstract}
The purpose of this study is to investigate factors that influence social media usage among small and medium enterprises (SMEs) and the impact on its performance. Convenience sampling was used to collect data. The respondent in this study are owner of SME that use facebook and instagram on their business activities. Based on SEM-PLS analysis, this study revealed that interactivity, cost effectiveness, and trust was identified as factors that motivate the usage social media. Meanwhile, compatibility has no significant effect on social media usage. Social media usage has a strong positive impact on financial performance (sales) and non-financialperformance of SMEs in terms of customer service, internal operations, and marketing. In addition, this study indicate that social media usage has no positive effects on perceived impact on innovation.
\end{abstract}

Keywords: social media, SME, performance, inovation, social commerce

\section{ABSTRAK}

Penelitian ini bertujuan menginvestigasi motivasi pelaku UMKM dalam pemanfaatan media sosial serta dampaknya terhadap kinerja UMKM.Metode survei dengan teknik convenience sampling digunakan dalam pengumpulan data.Responden penelitian ini adalah pelaku UMKM yang telah menggunakan media sosial facebook dan instagram dalam kegiatan bisnisnya.Hasil pengujian dengan SEM-PLS menunjukkan bahwa interaktivitas, efektivitas biaya dan kepercayaan merupakan faktor yang memotivasi pelaku UMKM untuk menggunakan media sosial.Sedangkan kompatibilitas tidak berpengaruh terhadap penggunaan media sosial.Penggunaan media sosial bagi UMKM berdampak positif terhadap kinerja UMKM yaitu kinerja pelayanan pelanggan, penjualan, pemasaran dan operasi internal.Akan tetapi tidak ditemukan bukti empiris pengaruh penggunaan media sosial terhadap kinerja inovasi.

Kata kunci: media sosial, UMKM, kinerja, inovasi, social commerce

\section{PENDAHULUAN}

UMKM memiliki peran strategis terhadap pertumbuhan ekonomi Indonesia, terutama di era globalisasi saat ini. Potensi UMKM sangat penting dengan perannya sebagai sumber pendapatan masyarakat, pemenuhan kebutuhan barang dan jasa domestik, penciptaan lapangan pekerjaan, serta peningkatan nilai tambah yang berdampak pada penurunan angka kemiskinan dan pertumbuhan ekonomi (Koperasi dan UMKM, 2015). Namun, UMKM juga mengalami berbagai macam permasalahan dan kendala. Berdasarkan rencana strategis Kementerian Koperasi dan UMKM tahun 2015-2019, upaya pemberdayaan UMKM difokuskan pada penanganan dua isu strategis, yaitu pertumbuhan usaha dan daya saing. 
Era globalisasi menjadi tantangan bagi UMKM untuk terus bertahan dan memiliki keunggulan bersaing. Berkembangnya teknologi informasi terutama media sosial menawarkan manfaat bagi UMKM untuk meningkatkan pemasaran dan penjualan, memperluas pangsa pasar, dan membantu pengambilan keputusan bisnis (Priambada, 2015). Berdasarkan data Asosiasi Penyelenggara Jasa Internet Indonesia (APJII), pengguna internet Indonesia tahun 2016 mencapai 51,8\% dari total penduduk yaitu sebesar 132,7 juta pengguna. Penggunaan internet sebagian besar untuk mengakses media sosial, hiburan dan onlineshop. Hal tersebut menjadikan potensi besar bagi UMKM di dunia maya terutama pada media sosial. Oleh karena itu, penting untuk menginvestigasi faktor-faktor yang memengaruhi motivasi penggunaan media sosial oleh UMKM.

Sebagian besar riset terdahulu terkait penggunaan media sosial oleh UMKM di Indonesia menggunakan penelitian kualitatif diantaranya yaitu metode studi kasus (Utami dan Purnama, 2012), penelitian deskriptif observasional mengenai implementasi media sosial terhadap pengembangan UMKM (Purwidiantoro dan Hadi, 2016), manfaat penggunaan media sosial (Priambada, 2015) dan media sosial sebagai media pemasaran (Siswanto, 2013). Studi eksplorasi mengenai faktor-faktor yang memengaruhi penggunaan media sosial secara kuantitatif belum banyak dilakukan, terutama dalam konteks UMKM.Sehingga motivasi pelaku bisnis UMKM dalam mengadopsi dan menggunakan media sosial dalam kegiatan bisnisnya masih belum dapat disimpulkan.

Studi terdahulu mengenai anteseden dan dampak penggunaan media sosial dalam konteks UMKM secara kuantitatif banyak dilakukan di negara maju.Riset di negara berkembang masih terbatas. Penelitian mengenai anteseden dan konsekuen penggunaan media sosial bagi UMKM dalam konteks negara berkembang dilakukan oleh (Odoom dkk. 2017). Riset tersebut menginvestigasi faktor-faktor yang mempengaruhi motivasi UMKM dalam adopsi dan penggunaan media sosial yaitu interaktivitas, efektivitas biaya, dan kompatibilitas dengan variabel outcomes hanya kinerja UMKM secara keseluruhan. Sehingga belum secara rinci dan detail dalam menggambarkan dampak manfaat penggunaan media sosial dalam aspek kinerja keuangan dan non keuangan.

Motivasi penelitian ini adalah mengisi gap dari penelitian terdahulu dengan menginvestigasi dampak kinerja secara lebih terperinci. Penelitian ini merupakan pengembangan dari riset Odoom dkk. (2017) dengan menggunakan lima dimensi kinerja pada variabel outcomes yang meliputi kinerja layanan pelanggan, penjualan, pemasaran, dan operasi internal (Schaupp dan Bélanger, 2014) dan menambahkan kinerja inovasi (Pérez-González dkk., 2017). Menurut Parida dkk. (2012), inovasi memiliki peran penting bagi UMKM dalam keunggulan bersaing dan mempertahankan keuntungan di pasar, sehingga UMKM harus terbuka terhadap inovasi.Selain itu, peneliti menambahkan anteseden kepercayaan (Ainin dkk. 2015) yang berperan penting dalam penentuan adopsi dan penggunaan suatu 
teknologi baru. Pelaku bisnis UMKM di negara berkembang cenderung slow adaptor, sehingga kepercayaan menjadi faktor penting dalam penentuan penggunaan media sosial.

\section{TINJAUAN LITERATUR DAN PENGEMBANGAN HIPOTESIS \\ The Diffussion Of Innovations Theory}

Teori Diffussion of Innovations mendasarkan pada proses penyebaran inovasi di dalam organisasi atau diantara individu yang menentukan keberhasilan dalam adopsi untuk berbagai macam tujuan. Inovasi dapat berupa produk, jasa, gagasan, informasi maupun praktik yang dianggap baru oleh individu (Rogers, 1995). Penelitian terdahulu terkait adopsi dan penggunaan inovasi teknologi secara umum mendasarkan pada Teori Diffussion of Innovations (Odoom dkk., 2017; Ainin, dkk., 2015). Menurut Odoom dkk. (2017), sebagai sistem pendukung untuk berbagai macam kebutuhan di berbagai konteks, penggunaan media sosial dalam konteks inovasi teknologi memerlukan penyebaran dan penyelarasan terhadap aktivitas perusahaan.

\section{Penggunaan Media Sosial Bagi UMKM}

Popularitas media sosial telah menciptakan sebuah paradigma baru ecommerce yang disebut social commerce.Social commerce merupakan bagian dari e-commerce dengan memanfaatkan interaksi sosial dan kontribusi pengguna media sosial dalam berbelanja online (Kim dan Park, 2013).Berdasarkan data Asosiasi Penyelenggara Jasa Internet Indonesia (APJII), sebagian besar pengguna internet Indonesia menggunakan internet untuk mengakses media sosial, hiburan dan onlineshop. Kegiatan perdagangan adalah aktivitas yang terbanyak dilakukan di media sosial yaitu sebesar 94,6\% (APJII, 2016). Fakta tersebut menunjukkan bahwa semakin banyak penjual yang memanfaatkan teknologi media sosial untuk bisnis online. Media sosial menjadi platform yang menguntungkan bagi pelaku binis dan konsumen untuk bertransaksi serta menjalin komunikasi yang intens (Kumar dkk., 2016). Media sosial sebagai suatu alat inovatif bagi UMKM dalam mendukung sistem bisnis. Oleh karena itu, penyebaran media sosial mencakup anteseden dalam adopsi, penggunaan dan konsekuen akan dapat dijabarkan dengan baik berdasarkan pada teori DOI (Odoom dkk., 2017). Studi ini menginvestigasi empat anteseden pada dua platform media sosial (facebook dan instagram) serta dampak penggunaan media sosial yang dijabarkan dalam lima kinerja secara lebih rinci.

\section{Interaktivitas}

Liu dan Shrum (2002) mendefinisikan interaktivitas sebagai tingkat interaksi antara dua pihak atau lebih di dalam media komunikasi dan kemampuan untuk merespon komunikan. Replies dan mentions merupakan fitur interaktif pada 
media sosial yang berguna untuk memudahkan pelaku bisnis dalam berkomunikasi dengan konsumen (Lovejoy, Waters, dan Saxton, 2012). Pertimbangan penting dalam mengadopsi media sosial adalah interaktivitas, karena fitur interaktivitas dapat menjembatani adanya gap yang disebabkan oleh perbedaan waktu dan lokasi geografis antara penjual dan konsumen (Michaelidou dkk., 2011). Hasil penelitian terdahulu menunjukkan bukti empiris pengaruh interaktivitas terhadap penggunaan media sosial bagi UMKM (Ainin dkk., 2015; Odoom dkk., 2017).

\section{H1: Interaktivitas berpengaruh positif terhadap penggunaan media sosial.}

\section{Efektivitas Biaya}

Literatur terdahulu menunjukkan bahwa efektifitas biaya menjadi variabel penting dalam menentukan adopsi sebuah teknologi baru (Chong dan Chan, 2012). Media sosial cocok dan sesuai untuk UMKM karena biaya rendah, hambatan partisipasi kecil dan tidak memerlukan penguasaan teknologi yang tinggi dalam mengoperasikannya (Derham, Cragg, dan Morrish, 2011). UMKM yang memiliki keterbatasan sumber daya akan mempertimbangkan penggunaan media sosial, karena media sosial dapat menghemat biaya (Hoffman \& Fodor, 2010). Hasil penelitian terdahulu menunjukkan bukti empiris pengaruh efektivitas biaya terhadap penggunaan media sosial bagi UMKM (Ainin dkk, 2015; Odoom dkk., 2017).

\section{H2: Efektivitas biaya berpengaruh positif terhadap penggunaan media} sosial.

\section{Kompatibilitas}

Kompatibilitas didefinisikan sebagai tingkat di mana sebuah inovasi sesuai dengan nilai, praktik dan kebutuhan dari potensial adopter (Chong \& Chan, 2012).Media sosial menawarkan fitur yang mempertemukan pilihan konsumen dan kebutuhan pasar.Hal ini tidak ada sebelumnya pada pemasaran tradisional. Pelaku bisnis dapat menemukan target konsumen secara efektif dan efisien melalui integritas aktivitas pada media sosial ke dalam operasi bisnis yang sejalur dengan nilai perusahaan (Derham dkk., 2011). Penelitian terdahulu menunjukkan bahwa UMKM cenderung untuk mempertimbangkan adopsi dan menggunakan media sosial berdasarkan pada kompatibilitas nilai dan tujuan perusahaan (Ainin dkk, 2015).

H3: Kompatibilitas berpengaruh positif terhadap penggunaan media sosial.

\section{Kepercayaan}

Bentuk kepercayaan yang berkaitan dengan penggunaan media sosial adalah kepercayaan informasi.Menurut (Chai dkk., 2011), kepercayaan informasi merupakan kepercayaan pengguna terkait dengan reliabilitas, kredibilitas dan 
akurasi informasi yang didapatkan dari media sosial. Kepercayaan informasi ini menjadi faktor penting dalam keputusan penggunaan media sosial.Faktor kesuksesan utama untuk UMKM dalam usahanya dapat diakomodasi melalui media sosial dengan terjalinnya hubungan relasi yang baik pada konsumen (Ainin dkk., 2015). Pelaku UMKM mem-posting berbagai macam informasi, ide, produk, jasa, dan aktivitas promosi lainnya melalui media sosial. Selain itu, pelaku UMKM juga mendapatkan berbagai macam pengetahuan dan informasi dari media sosial.Dengan demikian, diperlukan adanya kepercayaan informasi dalam penggunaan media sosial demi mencapai tujuan yang diharapkan (Ainin dkk., 2015).

\section{H4: Kepercayaan berpengaruh positif terhadap penggunaan media sosial.}

\section{Penggunaan Media Sosial dan Keuntungannya}

Berdasarkan pada uses and gratification theory, pengguna media sosial intens terlibat jika orientasi tujuannya terpenuhi dan termotivasi untuk memilih sebuah media yang menawarkan pemenuhan kebutuhan terbaik, sehingga kepuasan dapat diraih (Roy, 2009). Penggunaan media sosial secara khusus ditujukan untuk menarik pelanggan baru, memelihara hubungan dengan konsumen, meningkatkan kesadaran, mengkomunikasikan merek secara online, dan menerima umpan balik dari konsumen dan rekan bisnis (Michaelidou dkk., 2011). Pada akhirnya, keuntungan yang dihasilkan dari penggunaan media sosial adalah kinerja keuangan dan non keuangan.Temuan penelitian (Schaupp dan Bélanger, 2014) menunjukkan bukti empiris nilai media sosial Facebook yang berdampak pada kinerja UMKM meliputi layanan kepada pelanggan, penjualan, pemasaran dan operasi internal. Berdasarkan uraian tersebut, maka H5-H8 penelitian ini dapat dituliskan sebagai berikut.

\section{H5: Penggunaan media sosial berpengaruh positif terhadap kinerja pelayanan pelanggan.}
H6: Penggunaan media sosial berpengaruh positif terhadap kinerja penjualan.

\section{H7: Penggunaan media sosial berpengaruh positif terhadap kinerja pemasaran.}

H8: Penggunaan media sosial berpengaruh positif terhadap kinerja operasi internal.

Media sosial menyediakan berbagai macam informasi, salah satunya terkait dengan konsumen.Informasi yang didapatkan dari konsumen menjadi sumber penting untuk mengetahui kebutuhan dan pilihan konsumen.Sehingga UMKM memiliki kemampuan mengadaptasi dan meningkatkan produk yang sesuai dengan perubahan selera pasar untuk mencapai kesuksesan (Hung dan Chou, 2013). Media sosial memfasilitasi entitas bisnis dalam mengeksplorasi serta 
mendapatkan pengetahuan dan teknologi baru dari kompetitor melalui forum inovasi, blog, dan jejaring sosial profesional (Scuotto, Del Giudice, dan Carayannis, 2017). Hasil riset terdahulu menunjukkan bukti empiris penggunaan teknologi media sosial untuk mengakuisisi informasi pelanggan, informasi kompetitor dan knowledge sharing berpengaruh positif terhadap kinerja inovasi UMKM (Pérez-gonzález dkk., 2017).

H9: Penggunaan media sosial berpengaruh positif terhadap kinerja inovasi.

\section{METODE}

\section{Desain dan Sampel Penelitian}

Penelitian ini menggunakan metode survei yaitu metode pengumpulan data primer yang diperoleh secara langsung dari sumber asli melalui kuesioner. Desain penelitian ini menggunakan metode kuantitatif untuk menguji pengaruh variabel-variabel independen pada variabel dependen. Populasi riset ini adalah pelaku UMKM yang ada di wilayah Magelang dan Temanggung.Teknik nonprobability sampling digunakan dalam pemilihan sampel, yaitu metode convenience sampling dengan mengambil pelaku UMKM yang telah menggunakan media sosial dalam aktivitas bisnisnya, yaitu facebook dan instagram.

\section{Definisi Operasional dan Pengukuran Variabel Penelitian}

Item-item pengukuran variabel dalam penelitian ini diadopsi dari penelitian sebelumnya. Semua variabel diukur menggunakan skala Likert 5 poin, (1) Sangat Tidak Setuju (STS); (2) Tidak Setuju (TS); (3) Netral (N); (4) Setuju (S); (5) Sangat Setuju (SS). Definisi operasional variabel penelitian dapat dilihat pada Tabel 1.

Tabel 1. Definisi Operasional dan Pengukuran Variabel

\begin{tabular}{cclc}
\hline Konstruk & Pertanyaan & \multicolumn{1}{c}{ Definisi Operasional } & Referensi \\
\hline $\begin{array}{c}\text { Interaktivitas } \\
\text { (Reflektif) }\end{array}$ & 3 item & $\begin{array}{l}\text { Kemampuan media sosial } \\
\text { dalam merespon komunikasi } \\
\text { dari pelanggan. }\end{array}$ & $\begin{array}{c}\text { Ainin dkk. } \\
(2015)\end{array}$ \\
\hline $\begin{array}{c}\text { Efektivitas Biaya } \\
\text { (Reflektif) }\end{array}$ & 3 item & $\begin{array}{l}\text { Kemampuan media sosial } \\
\text { dalam menyediakan fiturnya } \\
\text { dengan biaya yang rendah. }\end{array}$ & $\begin{array}{c}\text { Ainin dkk. } \\
(2015)\end{array}$ \\
\hline $\begin{array}{c}\text { Kompatibilitas } \\
\text { (Reflektif) }\end{array}$ & 4 item & $\begin{array}{l}\text { Tingkat kesesuaian media } \\
\text { sosial terhadap kebutuhan, } \\
\text { nilai dan praktik dari UMKM. }\end{array}$ & $\begin{array}{c}\text { Chong dan Chan } \\
(2012)\end{array}$ \\
\hline $\begin{array}{c}\text { Kepercayaan } \\
\text { (Reflektif) }\end{array}$ & 5 item & $\begin{array}{l}\text { Tingkat kepercayaan pelaku } \\
\text { UMKM terhadap penggunaan } \\
\text { media sosial. }\end{array}$ & Chai dkk. \\
& & & \\
\hline
\end{tabular}




\begin{tabular}{|c|c|c|c|}
\hline $\begin{array}{c}\text { Penggunaan } \\
\text { Media Sosial } \\
\text { (Reflektif) }\end{array}$ & 6 item & $\begin{array}{l}\text { Faktor yang memengaruhi } \\
\text { UMKM untuk menggunakan } \\
\text { media sosial dan memberikan } \\
\text { nilai pada organisasi. }\end{array}$ & $\begin{array}{l}\text { Zhu, Kraemer, } \\
\text { dan Xu (2006) }\end{array}$ \\
\hline $\begin{array}{c}\text { Kinerja Pelayanan } \\
\text { Pelanggan } \\
\text { (Reflektif) }\end{array}$ & 4 item & $\begin{array}{l}\text { Persepsi manfaat yang } \\
\text { dirasakan UMKM dalam } \\
\text { penggunaan media sosial } \\
\text { untuk meningkatkan kepuasan } \\
\text { pelanggan. }\end{array}$ & $\begin{array}{c}\text { Schaupp dan } \\
\text { Bélanger (2014) }\end{array}$ \\
\hline $\begin{array}{l}\text { Kinerja Penjualan } \\
\text { (Formatif) }\end{array}$ & 2 item & $\begin{array}{l}\text { Persepsi manfaat yang } \\
\text { dirasakan UMKM dalam } \\
\text { penggunaan media sosial } \\
\text { terhadap penjualan. }\end{array}$ & $\begin{array}{l}\text { Picoto dkk., } \\
\text { (2012) }\end{array}$ \\
\hline $\begin{array}{l}\text { Kinerja Pemasaran } \\
\text { (Formatif) }\end{array}$ & 3 item & $\begin{array}{l}\text { Persepsi manfaat yang } \\
\text { dirasakan UMKM dalam } \\
\text { penggunaan media sosial } \\
\text { terhadap pemasaran. }\end{array}$ & $\begin{array}{c}\text { Picoto dkk., } \\
\text { (2012); Schaupp } \\
\text { dan Bélanger } \\
\text { (2014) }\end{array}$ \\
\hline $\begin{array}{l}\text { Kinerja Operasi } \\
\text { Internal } \\
\text { (Formatif) }\end{array}$ & 4 item & $\begin{array}{l}\text { Persepsi manfaat yang } \\
\text { dirasakan UMKM dalam } \\
\text { penggunaan media sosial } \\
\text { terhadap aktivitas bisnis } \\
\text { operasi internal UMKM. }\end{array}$ & $\begin{array}{l}\text { Picoto dkk., } \\
\quad(2012)\end{array}$ \\
\hline $\begin{array}{l}\text { Kinerja Inovasi } \\
\text { (Reflektif) }\end{array}$ & 4 item & $\begin{array}{l}\text { Persepsi manfaat yang } \\
\text { dirasakan UMKM dalam } \\
\text { penggunaan media sosial } \\
\text { terhadap inovasi. }\end{array}$ & $\begin{array}{l}\text { Pérez-González } \\
\text { dkk. (2017) }\end{array}$ \\
\hline
\end{tabular}

Sumber: berbagai literatur terdahulu

\section{Teknik Analisis Data dan Pengujian Hipotesis}

Model dalam penelitian ini diuji menggunakan SEM berbasis varian yaitu PLS (Partial Least Square) dengan bantuan software SmartPLS 3.0. SEM-PLS dapat bekerja secara efektif dengan ukuran sampel kecil dengan model yang kompleks dan dapat digunakan untuk konstruk reflektif dan formatif (Abdillah dan Hartono 2015). Pengujian dalam PLS dilakukan pada model pengukuran (outer model) dan model struktural (inner model).

\section{Model Pengukuran}

Pengujian pada model pengukuran terdiri dari uji validitas dan reliabilitas. Uji validitas terdiri dari convergent validity dan discriminant validity. Convergent validity digunakan untuk menilai seberapa besar korelasi antara dua ukuran dari konsep yang sama. Pengukuran convergent validity pada konstruk reflektif dihitung dengan nilai loading factor dan Average Variance Extracted (AVE) yaitu jumlah kuadrat standardized factor dibagi dengan jumlah item pengukuran. Rule of thumb dari loading factor di atas 0.7 dan nilai AVE harus lebih tinggi dari 0.5 (Hair dkk., 2014). Sedangkan pada konstruk formatif pengujian validitas menggunakan nilai weight dan Variance Inflation Factors (VIFs). 
Dicriminant validity merupakan penilaian seberapa berbeda suatu konstruk dengan konstruk lainnya, yaitu diukur dengan membandingkan nilai AVE dari kedua konstruk dengan nilai kuadrat korelasi antara dua konstruk yang diuji tersebut. Rule of thumb discriminant validity yaitu nilai akar kuadrat AVE lebih besar daripada korelasi antar konstruk dan nilai cross-loadings rendah (Hair dkk., 2014).

Uji reliabilitas digunakan untuk mengetahui konsistensi hasil dari pengukuran jika dilakukan pengukuran dua kali atau lebih terhadap gejala yang sama dengan alat ukur yang sama. Pengujian reliabilitas dilakukan dengan pengukuran yang memenuhi kriteria nilai composite reliability di atas 0,7 meskipun 0,6 masih dapat diterima (Hair dkk., 2014). Semakin besar nilai cronbach's alpha maka semkin tinggi tingkat reliabilitas alat ukur yang digunakan.

\section{Model Struktural}

Inner model merupakan model struktural untuk memprediksi hubungan kausalitas antar variabel laten. Uji model menggunakan parameter nilai R-Square $\left(\mathrm{R}^{2}\right)$. Semakin tinggi nilai $\mathrm{R}^{2}$, maka semakin baik model penelitian. Tingkat signifikansi dalam pengujian hipotesis ditunjukkan oleh nilai koefisien path (inner model). Rule of thumb skor koefisien yang ditunjukkan oleh nilai $t$-statistic harus di atas 1,64 untuk hipotesis one tailed pada pengujian hipotesis dengan menggunakan alpha 5\% (Hair dkk., 2014). Pengujian hipotesis dalam penelitian ini diterima jika menunjukkan nilai p-value $<0,05$.

\section{HASIL PENGUJIAN HIPOTESIS DAN PEMBAHASAN}

Sebanyak 95 UMKM dengan berbagai macam industri menjadi sampel dalam penelitian ini.Akan tetapi, terdapat 8 responden yang dikeluarkan karena tidak mengisi kuesioner secara lengkap.Akhirnya, total sampel dalam penelitian ini adalah 87 responden.Karakteristik responden dalam penelitian ini ditunjukkan pada Tabel 2.

Tabel 2. Karakteristik Responden

\begin{tabular}{cllcl}
\hline No. & \multicolumn{2}{c}{ Karakteristik Responden } & \multicolumn{2}{c}{ Jumlah } \\
\hline 1. & \multirow{2}{*}{ Jenis Kelamin } & Laki-laki & 34 & $40 \%$ \\
& & Perempuan & 53 & $60 \%$ \\
\hline 2. & Usia & $21-24$ tahun & 27 & $31 \%$ \\
& & $25-30$ tahun & 36 & $41 \%$ \\
& & $31-35$ tahun & 8 & $9 \%$ \\
& & $36-40$ tahun & 1 & $1 \%$ \\
& & $41-50$ tahun & 9 & $10 \%$ \\
& & diatas 50 tahun & 6 & $7 \%$ \\
\hline 3. & Pendidikan & SMA/K & 52 & $60 \%$ \\
& Terakhir & Diploma (D3) & 4 & $4 \%$ \\
& & Sarjana (S1) & 31 & $36 \%$ \\
\hline
\end{tabular}




\begin{tabular}{cclcl}
\hline 4. & Bidang Usaha & Kuliner & 46 & $53 \%$ \\
& & Fotografi & 4 & $5 \%$ \\
& & Kerajinan & 12 & $14 \%$ \\
& & Merchandise & 25 & $29 \%$ \\
\hline 5. & Lama Berdiri & $1-3$ tahun & 48 & $55 \%$ \\
& & $4-6$ tahun & 6 & $7 \%$ \\
& & $7-9$ tahun & 15 & $17 \%$ \\
& & diatas 9 tahun & 19 & $21 \%$ \\
\hline
\end{tabular}

\section{Model Pengukuran (Outer Model)}

Pengujian validitas dan reliabilitas konstruk reflektif menunjukkan bahwa semua item telah memenuhi persyaratan. Berdasarkan hasil uji validitas di Tabel 3 , nilai loading factor pada semua item di atas 0.7 dan nilai AVE lebih tinggi dari 0.5 . Sedangkan pada uji reliabilitas menunjukkan nilai $C R>0,7$ pada semua konstruk dan cronbach's alpha $>0,7$. Dengan demikian, dapat dinyatakan semua konstruk pada penelitian ini reliabel.

Tabel 3. Pengujian Validitas dan Reliabilitas Konstruk Reflektif

\begin{tabular}{|c|c|c|c|c|c|}
\hline & $\begin{array}{l}\text { Construct } \\
\text { Items }\end{array}$ & $\begin{array}{l}\text { Standardized } \\
\text { Loading }\end{array}$ & $\begin{array}{l}\text { Composite } \\
\text { Reliability }\end{array}$ & $A V E$ & $\begin{array}{l}\text { Cronbach's } \\
\text { Alpha }\end{array}$ \\
\hline \multirow{3}{*}{ Interaktivitas } & INT1 & 0,784 & \multirow{3}{*}{0,709} & \multirow{3}{*}{0,602} & \multirow{3}{*}{0,702} \\
\hline & INT2 & 0,741 & & & \\
\hline & INT3 & 0,899 & & & \\
\hline \multirow{3}{*}{ Efektivitas Biaya } & EB1 & 0,912 & \multirow{3}{*}{0,881} & \multirow{3}{*}{0,715} & \multirow{3}{*}{0,804} \\
\hline & EB2 & 0,892 & & & \\
\hline & EB3 & 0,718 & & & \\
\hline \multirow{4}{*}{ Kompatibilitas } & KOM1 & 0,775 & \multirow{4}{*}{0,856} & \multirow{4}{*}{0,601} & \multirow{4}{*}{0,785} \\
\hline & KOM2 & 0,712 & & & \\
\hline & KOM3 & 0,734 & & & \\
\hline & KOM4 & 0,867 & & & \\
\hline \multirow{5}{*}{ Kepercayaan } & $\mathrm{KPC} 1$ & 0,896 & \multirow{5}{*}{0,875} & \multirow{5}{*}{0,685} & \multirow{5}{*}{0,829} \\
\hline & KPC2 & 0,709 & & & \\
\hline & KPC3 & 0,707 & & & \\
\hline & KPC4 & 0,754 & & & \\
\hline & KPC5 & 0,770 & & & \\
\hline
\end{tabular}

\begin{tabular}{llllll}
\hline & PMS1 & 0,734 & & & \\
& PMS2 & 0,824 & & & \\
Penggunaan Media & PMS3 & 0,726 & 0,893 & 0,585 & 0,857 \\
Sosial & PMS4 & 0,802 & & & \\
& PMS5 & 0,730 & & & \\
& PMS6 & 0,759 & & & \\
& PP1 & 0,782 & 0,890 & 0,658 & 0,839 \\
Kinerja Pelayanan & PP2 & 0,783 & & &
\end{tabular}




\begin{tabular}{llllll} 
& PP3 & 0,871 & & & \\
& PP4 & 0,832 & & & \\
\hline \multirow{3}{*}{ Kinerja Inovasi } & INV1 & 0,751 & & & \\
& INV2 & 0,872 & 0,908 & & \\
& INV3 & 0,908 & & & \\
\hline
\end{tabular}

Berdasarkan pada hasil pengujian validitas pada konstruk formatif yang ditunjukkan Tabel 4 menunjukkan bahwa nilai weights pada semua konstruk signifikan, kecuali pada PSR2, OI2, OI3, dan OI4. Hal ini mengindikasikan validitas terpenuhi.Indikator tersebut tetap dipertahankan dalam model dan tidak dikeluarkan mengingat setiap item merepresentasikan dimensi yang berbeda dari kepentingan konstruk formatif dan untuk mempertahankan validitas konten (Chin, 2010 dalam Schaupp \& Belanger 2014).Hasil pengujian multikolinearitas dengan menggunakan nilai VIFs menunjukkan bahwa semua item pada konstruk formatif memiliki nilai VIFs di bawah cutoff sebesar 3.3. Hal tersebut mengindikasikan tidak terjadi masalah multikolinearitas (Diamantopoulos dan Siguaw 2006).

Tabel 4. Pengujian Validitas Konstruk Formatif

\begin{tabular}{lcccc}
\hline Konstruk & $\begin{array}{l}\text { Construct } \\
\text { Items }\end{array}$ & $\begin{array}{l}\text { Standardized } \\
\text { Loading }\end{array}$ & Significance & VIF \\
\hline \multirow{2}{*}{ Kinerja Penjualan } & PJL1 & 0.676 & 0.004 & 1.292 \\
& PJL2 & 0,482 & 0,048 & 1.292 \\
& PSR1 & 0.745 & 0.000 & 1.489 \\
Kinerja Pemasaran & PSR2 & 0.189 & $\mathrm{~ns}$ & 1.408 \\
& PSR3 & 0.582 & 0.001 & 1.108 \\
\multirow{3}{*}{ Kinerja Operasi } & OI1 & 0.975 & 0.000 & 1.357 \\
Internal & OI2 & 0.179 & $\mathrm{~ns}$ & 1.687 \\
& OI3 & 0.459 & $\mathrm{~ns}$ & 2.370 \\
& OI4 & 0.567 & $\mathrm{~ns}$ & 2.775 \\
\hline
\end{tabular}

Hasil pengujian dicriminant validity yang dirinci pada Tabel 5 menunjukkan bahwa semua konstruk dalam model penelitian ini telah memenuhi persyaratan. Pada setiap konstruk yang diuji, nilai akar kuadrat AVE lebih besar daripada korelasi antar konstruk. Hal ini mengindikasikan bahwa validitas diskriminan terpenuhi.

Tabel 5. Pengujian Validitas Diskriminan

\begin{tabular}{lllllllllll}
\hline Konstruk & EB & INT & INV & KOM & KPC & OI & PJL & PMS & PP & PSR \\
\hline EB & $\mathbf{0 . 8 4 5}$ & & & & & & & & & \\
INT & 0.316 & $\mathbf{0 . 7 0 3}$ & & & & & & & & \\
INV & 0.179 & 0.164 & $\mathbf{0 . 8 4 5}$ & & & & & & & \\
KOM & 0.423 & 0.482 & 0.348 & $\mathbf{0 . 7 7 4}$ & & & & & & \\
KPC & 0.400 & 0.361 & 0.439 & 0.478 & $\mathbf{0 . 7 6 5}$ & & & & & \\
OI & 0.491 & 0.361 & 0.172 & 0.378 & 0.404 & NA & & & \\
\hline
\end{tabular}




\begin{tabular}{llllllllllll}
\hline PJL & 0.334 & 0.518 & 0.078 & 0.371 & 0.336 & 0.390 & NA & & & \\
PMS & 0.523 & 0.515 & 0.187 & 0.482 & 0.460 & 0.488 & 0.420 & $\mathbf{0 . 7 6 4}$ & & \\
PP & 0.492 & 0.441 & 0.198 & 0.501 & 0.477 & 0.409 & 0.308 & 0.529 & $\mathbf{0 . 8 1 8}$ & \\
PSR & 0.558 & 0.388 & 0.085 & 0.520 & 0.440 & 0.414 & 0.452 & 0.439 & 0.453 & NA \\
\hline
\end{tabular}

\section{Model Struktural}

Pengujian model struktural menunjukkan bahwa nilai R2 pada penggunaan media sosial sebesar 45,2\%. Sedangkan pada dimensi dampak kinerja, nilai R2 untuk kinerja pelayanan pelanggan 28\%, kinerja operasi internal sebesar 23,8\%, kinerja pemasaran sebesar 19,2\%, kinerja penjualan sebesar 17,7\% dan kinerja inovasi sebesar 3,5\%.Dari empat hipotesis yang diajukan sebagai anteseden penggunaan media sosial bagi UMKM, hanya tiga hipotesis yang terdukung. Motivasi pelaku UMKM dalam menggunakan media sosial dipengaruhi oleh faktor efektivitas biaya $(0,308)$, adanya fitur interaktivitas $(0,294)$ dan kepercayaan terhadap media sosial $(0,169)$. Berdasarkan pada hasil path analisis menunjukkan bahwa tingkat signifikansi di bawah 0,05 sehingga mendukung $\mathrm{H} 1$, $\mathrm{H} 2$, dan H4. Kompatibilitas (H3) tidak berpengaruh signifikan terhadap penggunaan media sosial bagi UMKM dengan signifikansi sebesar 0,085.

Tabel 6. Pengujian Hipotesis

\begin{tabular}{lcccc}
\hline \multicolumn{1}{c}{ Hipotesis } & $\begin{array}{c}\text { Structural } \\
\text { loading }\end{array}$ & t-statistic & p-values & Keterangan \\
\hline H1 : INT $\rightarrow$ PMS & 0.294 & 3.449 & 0.000 & Terdukung \\
H2 : EB $\rightarrow$ PMS & 0.308 & 3.428 & 0.000 & Terdukung \\
H3 : KOM $\rightarrow$ PMS & 0.130 & 1.375 & 0.085 & Tidak Terdukung \\
H4 : KPC $\rightarrow$ PMS & 0.169 & 1.880 & 0.030 & Terdukung \\
H5 : PMS $\rightarrow$ PP & 0.529 & 9.332 & 0.000 & Terdukung \\
H6 : PMS $\rightarrow$ PJL & 0.420 & 5.291 & 0.000 & Terdukung \\
H7 : PMS $\rightarrow$ PSR & 0.439 & 6.333 & 0.000 & Terdukung \\
H8 : PMS $\rightarrow$ OI & 0.488 & 3.905 & 0.000 & Terdukung \\
H9 : PMS $\rightarrow$ INV & 0.187 & 1.534 & 0.063 & Tidak Terdukung \\
\hline
\end{tabular}

Nilai path terbesar untuk model penggunaan media sosial dan dampak terhadap kinerja ada pada kinerja pelayanan pelanggan sebesar 0,529. Selanjutnya pada kinerja operasi internal sebesar 0,488, kinerja pemasaran sebesar 0,439 dan terkahir pada kinerja penjualan sebesar 0,420 . Nilai path dari keempat dimensi tersebut signifikan pada $\mathrm{p}<0,0001$, hal ini mengindikasikan bahwa H5, H6, H7, dan H8 penelitian ini terdukung. Sedangkan kinerja inovasi memiliki nilai signifikansi di bawah 0,05 yaitu sebesar 0,063. Dengan demikian H9 tidak terdukung. Hasil pengujian hipotesis menggunakan bootstraping secara rinci dapat dilihat pada Tabel 6 .

\section{Interaktivitas terhadap Penggunaan Media Sosial}

Berdasarkan hasil pengujian, interaktivitas berpengaruh positif terhadap penggunaan media sosial bagi UMKM.Hal ini berarti H1 terdukung. Ketersediaan 
komunikasi dua arah secara interaktif antara penjual dan konsumen menjadi faktor penting dalam penggunaan media sosial. Media sosial seperti facebook dan instagram menyediakan fitur interaktif seperti menu obrolan pribadi,replies dan mentions/tag yang memudahkan pelaku bisnis untuk menjalin komunikasi dengan konsumen. Adanya fitur interaktivitas tersebut dapat mempercepat respon penjual terhadap kebutuhan konsumen karena menjembatani perbedaan waktu dan lokasi antara penjual dan konsumen.Fitur interaktif yang ditawarkan media sosial dapat menjadi wadah bagi penjual dan pelanggan untuk melakukan co-creation terhadap produk. Sehingga keinginan konsumen seperti kustomisasi produk dapat terfasilitasi melalui fitur yang ada pada media sosial.Hasil penelitian ini mendukung riset terdahulu (Ainin dkk., 2015; Odoom dkk., 2017).

\section{Efektivitas Biaya terhadap Penggunaan Media Sosial}

Penelitian ini menemukan bukti empiris pengaruh positif efektivitas biaya terhadap penggunaan media sosial bagi UMKM, sehingga mendukung H2.Faktor utama yang memotivasi pelaku UMKM dalam penggunaan media sosial adalah efektivitas biaya.Sebagian besar bisnis berskala kecil seperti UMKM cenderung mengalami keterbatasan modal.Oleh karena itu, para pelaku bisnis UMKM memanfaatkan peluang dengan menggunakan media sosial untuk menunjang aktivitas bisnis dengan biaya yang rendah.Melalui media sosial, UMKM dapat menghemat biaya dalam komunikasi pemasaran, promosi, dan iklan.Selain itu, penggunaan media sosial facebook dan instagram lebih efektif dan memangkas biaya dibandingkan dengan media tradisional dalam pemasaran, branding dan layanan pelanggan.Temuan empiris ini sejalan dengan hasil penelitian yang telah dilakukan Chong dan Chan (2012) dan Ainin dkk. (2015).

\section{Kompatibilitas terhadap Penggunaan Media Sosial}

Penelitian ini tidak menemukan bukti empiris pengaruh kompatibilitas terhadap penggunaan media sosial bagi UMKM, sehingga $\mathrm{H} 3$ tidak terdukung. Adanya kesesuaian media sosial dengan kebutuhan dan praktek bisnis UMKM tidak terbukti berpengaruh terhadap penggunaan media sosial. Meskipun facebook dan instagram merupakan aplikasi media sosial yang simpel, hanya dengan perangkat mobile seperti smartphone dan koneksi internet dapat dijalankan.Akan tetapi, sebagian pemilik bisnis UMKM terutama yang berusia lanjut menyerahkan kepada admin atau karyawan dalam urusan penggunaan media sosial. Faktor usia dan kemauan untuk belajar teknologi baru menjadi pertimbangan tersendiri dalam penggunaan media sosial untuk aktivitas bisnis bagi UMKM. Walaupun media sosial mudah dipelajari dan tidak membutuhkan tenaga ahli dalam bidang TI dalam mengoperasikannya, pemilik bisnis UMKM juga mempertimbangkan biaya 
dan manfaat untuk menggaji karyawan yang dikhususkan mengelola media sosial dalam aktivitas bisnisnya.

\section{Kepercayaan Terhadap Penggunaan Media Sosial}

Berdasarkan hasil pengujian, kepercayaan berpengaruh positif terhadap penggunaan media sosial bagi UMKM sehingga $\mathrm{H} 4$ penelitian ini terdukung.Faktor kepercayaan pelaku bisnis UMKM terkait dengan reliabilitas, kredibilitas dan akurasi informasi yang didapatkan dari media sosial merupakan faktor yang memengaruhi penggunaan media sosial.Pelaku UMKM memiliki kepercayaan bahwa lingkungan media sosial menyediakan sarana yang aman untuk bertransaksi informasi dan melindungi informasi yang diposkan.Lebih lanjut, adanya tindakan hukum seperti UU ITE (Informasi dan Transaksi Elektronik) dan teknologi yang memadai untuk mengatasi masalah penggunaan media sosial juga menjadi faktor pendorong pelaku UMKM dalam adopsi dan penggunaan media sosial.

\section{Penggunaan Media Sosial terhadap Kinerja}

Hasil penelitian ini menunjukkan bahwa penggunaan media sosial memberikan dampak keuntungan kinerja keuangan dan non keuangan bagi UMKM.Dengan demikian, H5-H8 penelitian ini terdukung.Kinerja keuangan diwakili oleh persepsi atas penjualan dan kinerja non keuangan meliputi kinerja pelayanan pelanggan, pemasaran dan operasi internal. Dengan demikian, pemanfaatan media sosial memberikan dampak manfaat terhadap peningkatan kinerja UMKM baik non keuangan maupun keuangan.Oleh karena itu, optimalisasi penggunaan media sosial dapat menjadi keunggulan bersaing bagi UMKM di era globalisasi ini.

Berdasarkan hasil pengujian, dampak manfaat kinerja pada pelayanan pelanggan merupakan dampak terbesar atas pemanfaatan media sosial.Hal tersebut mengindikasikan bahwa peran utama media sosial dalam aktivitas bisnis UMKM yaitu memberikan kemudahan dalam berkomunikasi dan memelihara hubungan antara penjual dan konsumen. Dengan demikian kepuasan pelanggan akan meningkat. Dampak manfaat berikutnya yaitu pada kinerja operasi internal yang ditandai dengan semakin meningkatnya produktivitas karyawan.Media sosial dapat membantu pekerjaan karyawan menjadi lebih efisien, misalnya pada bagian promosi.Selain itu, dampak pada kinerja pemasaran dengan mendorong karyawan menjadi lebih berinisiatif dalam melakukan promosi dengan adanya media sosial.Manfaat penggunaan media sosial yang terakhir adalah pada kinerja penjualan.Pemanfaatan media sosial oleh UMKM dapat meningkatkan penjualan dan memperluas area penjualan. Terbukti bahwa UMKM yang mampu menyesuaikan dengan perkembangan teknologi seperti media sosial akan lebih unggul dalam persaingan di pasar. 
Penelitian ini tidak menemukan bukti empiris dampak penggunaan media sosial terhadap kinerja inovasi, sehingga H9 tidak terdukung. Sampel dalam riset ini sebagian besar bergerak pada industri kuliner dengan lama berdiri antara satu sampai tiga tahun dengan skala usaha mikro. Dengan demikian, inovasi baik produk, praktik manajemen dan metode pemasaran belum begitu terlihat. Fokus utama pada bisnis yang belum lama berdiri yaitu pada pemeliharaan pelanggan, sehingga inovasi bukan menjadi fokus terpenting. Sebagian besar bisnis baru juga muncul dari kreativitas dan inovasi dari bisnis pesaingnya. Oleh karena itu, ketika bisnis telah berjalan, inovasi bukanlah menjadi prioritas utama.

\section{KESIMPULAN, KETERBATASAN, DAN SARAN}

Penelitian ini menginvestigasi faktor-faktor yang memotivasi pelaku UMKM dalam pemanfaatan media sosial (social commerce) pada platform facebook dan instagram serta dampaknya terhadap kinerja keuangan dan non keuangan. Berdasarkan pengujian ditemukan bukti empiris pengaruh interaktivitas, efektivitas biaya, dan kepercayaan terhadap penggunaan media sosial. Sedangkan kompatibilitas tidak berpengaruh terhadap motivasi pelaku UMKM dalam menggunakan media sosial untuk menunjang kegiatan bisnisnya. Faktor pendorong utama bagi pelaku UMKM dalam pemanfaatan social commerce yaitu efektivitas biaya. Pelaku UMKM menggunakan media sosial dalam menunjang aktivitas bisnisnya karena dapat memangkas biaya operasional.

Selanjutnya, penggunaan media sosial memberikan dampak berupa keuntungan terhadap kinerja UMKM yang meliputi kinerja keuangan yang diukur dengan persepsi penjualan dan kinerja non keuangan pada pelayanan pelanggan, penjualan, pemasaran, dan operasi internal. Penelitian ini tidak menemukan bukti empiris pengaruh penggunaan media sosial terhadap kinerja inovasi.

Penelitian ini memiliki keterbatasan dalam jumlah dan cakupan wilayah sampel, sehingga terbatas dalam generalisasi hasil penelitian. Saran untuk penelitian selanjutnya agar memperluas sampel penelitian pada wilayah dan jenis industri yang lebih beragam. Penelitian ini tidak menemukan bukti empiris dampak pengaruh penggunaan media sosial terhadap kinerja inovasi. Sampel penelitian ini sebagian besar bergerak dalam bidang industri kuliner dengan skala mikro dan tergolong bisnis baru, sehingga inovasi bukan menjadi fokus utama. Riset selanjutnya dapat menggunakan jenis industri yang memiliki tingkat persaingan tinggi dengan skala industri yang lebih besar.

\section{REFERENSI}

Abdillah, W. dan J. Hartono . 2015. Partial Least Square (PLS) Alternatif SEM dalam Penelitian Bisnis. Yogyakarta: Penerbit Andi.

Ainin, S., Parveen, F., Moghavvemi, S., Jaafar, N. I., \& Mohd Shuib, N. L. 2015. Factors influencing the use of social media by SMEs and its performance 
outcomes. Industrial Management \& Data Systems, 115(3): 570-588. https://doi.org/10.1108/IMDS-07-2014-0205.

APJII, A. P. J. I. 2016. Penetrasi dan Perilaku Pengguna Internet Indonesia. Infografis Hasil Survey 2016: 1-35.

Chai, S., Das, S., \& Rao, H. R. 2011. Factors Affecting Bloggers' Knowledge Sharing: An Investigation Across Gender. Journal of Management Information Systems, 28(3): 309-342. https://doi.org/10.2753/MIS07421222280309.

Chong, A. Y.-L., \& Chan, F. T. S. 2012. Structural Equation Modeling for MultiStage Analysis on Radio Frequency Identification (RFID) Diffusion in The Health Care Industry. Expert Systems with Applications, 39(10): 8645-8654. https://doi.org/10.1016/j.eswa.2012.01.201

Derham, R., Cragg, P., \& Morrish, S. 2011. Creating Value: An SME And Social Media. Creating Value: An SME and Social Media, (January 2011): 1-9.

Hair, J. F., W. C. Black, B. J. Babin, and R. E. A. 2014. Multivariate Data Analysis 7 th edition. Pearson Education Limited.

Hoffman, D. D. L. D. L., \& Fodor, M. 2010. Can You Measure the ROI of Your Social Media Marketing? MIT Sloan Management Review, 52(1): 41-49. https://doi.org/10.1287/mksc.1120.0768

Hung, K. P., \& Chou, C. 2013. The Impact of Open Innovation on Firm Performance: The Moderating Effects of Internal R\&D and Environmental Turbulence. Technovation, 33(10-11): 368-380. https://doi.org/10.1016/j.technovation.2013.06.006

Kim, S., \& Park, H. 2013. Effects of Various Characteristics of Social Commerce (S-Commerce) on Consumers' Trust and Trust Performance. International Journal Of Information Management, 33(2): 318-332. https://doi.org/10.1016/j.ijinfomgt.2012.11.006.

Koperasi dan UMKM, K. 2015. Rencana Strategis Kementrian Koperasi dan UMKM Republik Indonesia 2015-2019. Retrieved from www.depkop.go.id.

Kumar, A., Bezawada, R., Rishika, R., Janakiraman, R., \& Kannan, P. K. 2016. From Social to Sale: The Effects of Firm-Generated Content in Social Media on Customer Behavior. Journal of Marketing, 80(1): 7-25. https://doi.org/10.1509/jm.14.0249.

Liu, Y., \& Shrum, L. J. 2002. What is Interactivity and is It Always Such A Good Thing? Implications of Definition, Person, and Situation for The Influence of 
Interactivity on Advertising Effectiveness. Journal of Advertising, 31(4): 5364. https://doi.org/10.1080/00913367.2002.10673685.

Lovejoy, K., Waters, R. D., \& Saxton, G. D. 2012. Engaging Stakeholders Through Twitter: How Nonprofit Organizations ArelNgetting More Out of 140 Characters or Less. Public Relations Review, 38(2): 313-318. https://doi.org/10.1016/j.pubrev.2012.01.005.

Michaelidou, N., Siamagka, N. T., \& Christodoulides, G. 2011. Usage, Barriers and Measurement of Social Media Marketing: An Exploratory Investigation of Small And Medium B2B Brands. Industrial Marketing Management, 40(7), 1153-1159. https://doi.org/10.1016/j.indmarman.2011.09.009.

Odoom, R., Anning-Dorson, T., \& Acheampong, G. 2017. Antecedents of Social Media Usage and Performance Benefits In Small- And Medium-Sized Enterprises (SMEs). Journal of Enterprise Information Management, 30(3): 383-399. https://doi.org/10.1108/JEIM-04-2016-0088.

Parida, V., Westerberg, M. and Frishammar, J. 2012, Inbound Open Innovation Activities In High-Tech SMEs: The Impact on Innovation Performance, Journal of Small Business Management, Vol. 50(2): 283-309.

Pérez-gonzález, D., Trigueros-preciado, S., \& Popa, S. 2017. Social Media Technologies. Use for the Competitive Information and Knowledge Sharing, and Its Effects on Industrial SMEs. Innovation Social Media Technologies Use for the Competitive Information and Knowledge. Information Systems Management, 34(3): 291-301. https://doi.org/10.1080/10580530.2017.1330007.

Picoto, W., Belanger, F., \& Palma-dos-Reis, A. 2012. Leveraging on Mobile Business to Enhance Firm Performance: An Organizational Level Study. Ecis, (2012): Paper 113.

Priambada, S. 2015. Manfaat Penggunaan Media Sosial Pada Usaha Kecil Menegah (UMKM), Seminar Nasional Sistem Informasi Indonesia (November): 41-46.

'Purwidiantoro, M. H., S.W, K. D. F., \& Hadi, W. 2016. Pengaruh Penggunaan Media Sosial terhadap Pengembangan Usaha Kecil Menengah (UMKM). Jurnal EKA CIDA, 1(1): 30-39.

Rogers, E. M. 1995. Diffusion of innovations. Macmillian Publishing Co. https://doi.org/citeulike-article-id: 126680

Roy, S. K. 2009. Internet uses and gratifications: A survey in the Indian context. Computers in Human Behavior, 25(4): 878-886. https://doi.org/10.1016/j.chb.2009.03.002 
Schaupp, L. C., \& Bélanger, F. 2014. The Value of Social Media for Small Businesses. Journal of Information Systems, 28(1): 187-207. https://doi.org/10.2308/isys-50674

Scuotto, V., Del Giudice, M., \& Carayannis, E. G. 2017. The Effect of Social Networking Sites and Absorptive Capacity on SMES' Innovation Performance. Journal of Technology Transfer, 42(2): 409-424. https://doi.org/10.1007/s10961-016-9517-0

Siswanto, T. 2013. Optimalisasi Sosial Media Sebagai Media Pemasaran Usaha Kecil Menengah. Liquidity, 2(1): 80-86.

Utami, A. D., \& Purnama, B. E. 2012. Pemanfaatan Jejaring Sosial Sebagai Media Bisnis Online (Studi Kasus di Batik Solo 85). Seruni FTI UNSA, 1, 1-7.

Zhu, K., Kraemer, K. L., \& Xu, S. 2006. The Process of Innovation Assimilation by Firms in Different Countries: A Technology Diffusion Perspective on EBusiness. $\quad$ Management Science, 52(10): 1557-1576. https://doi.org/10.1287/mnsc.1050.0487 